\title{
27. \\ FRANCUSKA I INTELEKTUALCI \\ KRALJEVINE JUGOSLAVIJE KRAJEM \\ 1930-TIH
}

\section{Veljko Stanić}

UDK: $316.344 .32(44=163.41 / .42) " 193$ “

Izvorni znanstveni članak

Sažetak: U radu se analizira odnos intelektualaca Kraljevine Jugoslavije prema Francuskoj krajem 1930-tih godina. U središtu pažnje je srpski liberalni intelektualni krug, koji je u svom političkom, ideološkom i kulturnom vidokrugu negovao posebno mesto za francusku kulturu, a u godinama pred Drugi svetski rat reafirmisao ključne odrednice svojih ideoloških i kulturnih opredeljenja za francusku civilizaciju. Kroz periodiku i posebne publikacije koji datiraju iz 1938, 1939. i 1940. godine, analiziraju se temeljna određenja slike Francuske koju stvara i reprodukuje ovaj intelektualni milje. Na primeru javnih istupa ovog kruga propituju se elementi njegovog ideološkog profila, kako bi se osvetlila figura liberalnog intelektualca u Kraljevini Jugoslaviji. Smeštajući je u teorijski okvir koji pruža savremena francuska istoriografija, rad želi da doprinese razvoju istorije intelektualaca u srpskoj istoriografiji.

Ključne reči: Francuska, Jugoslavija, intelektualci, kultura, ideologije, liberalizam

bilazeći beogradske antikvarijate nakon završetka Drugog svetskog rata - pronalazeći u njima i ukradene i razvučene knjige svoje nekada otmene biblioteke - Branko Lazarević je zapisao:

Prema onome što se prodaje, vidi se jasno da je Beograd bio vrlo francuski orijentisan. $\mathrm{Na}$ sto knjiga, skoro ih je devedeset francuskih. Ima tu svih knjiga Ašeta, Alkana, N. E. F., Plona, Larusa, i velikih kolekcija kakve su Nouvelle philosophie scientifique, Philosophie contemporaine, Evolution de l'humanité. (...) Posmatranje tih antikvarskih knjižara je vrlo zanimljiv presek kroz predratnu istoriju Beograda. U tome se preseku vide „strate” našeg kulturnog razvitka. ${ }^{1}$

Kulturni razvitak koji pominje Lazarević podrazumeva pogled unazad i to naročito u poluvekovnom luku koji spaja vreme Fin de siècle-a i ono četrdesetih godina koje i za samog Lazarevića predstavljaju kraj ,jučerašnjeg sveta”. U tih pola veka kulturne istorije, francu-

Бранко ААЗАРЕВИТ, Аневник једнога никога, Аруги део (1947), БеограА 2007., 394. 
ska kultura ulazi u matične tokove srpske i, samo delimično, jugoslovenske kulturne scene. Početkom dvadesetog veka se tako unutar kruga oko Srpskog književnog glasnika utvrđuje, ponajviše aproprijacijom francuskih obrazaca, liberalni kulturni model koji u nauci odgovara pozitivizmu, u estetskom svetu Parnasu, a u političkom i nacionalnom ključu gravitira jugoslovenskom rešenju. ${ }^{2}$ Međutim, $u$ istom periodu se na „slovenskom jugu” javlja i izraz jedne iracionalne estetike koja svoja modernistička nadahnuća velikim delom crpe iz francuskih izvora. Tokom narednih decenija, nekoliko generacijskih krugova, posebno unutar srpske literarne, umetničke i filozofske scene, biće vezani za Francusku kao nesumnjivi duhovni okvir. Nimalo slučajno, oni će zauzeti dominantno mesto u domaćem kulturnom životu: najpre naraštaj čiji je ukus ostao duboko u 19. veku i zastao na larpulartizmu, gajeći otmen odnos prema sintezi francuskog klasicizma i racionalizma; zatim intelektualni krug koji je ponajviše delio dileme i zapitanosti jednog Pola Valerija (Paul Valéry), dovodeći u vezu estetizam i moderni lirski izraz sa sudbinom evropske civilizacije i potrebom međunarodne intelektualne saradnje; krug bergsonovaca čija učenja su navodila na osmišljavanje jedne duge jugoslovenske „evolucije”; najzad, nadrealistički krug koji je unutar međunarodne kulturne scene uspostavio ravnopravnost u dijalogu sa pariskim nadrealistima, osporavajući sa svojih avangardnih pozicija sve što mu je prethodilo.

Problematizovanje ovih intelektualnih generacija jedno je od ključnih pitanja srpske i jugoslovenske intelektualne istorije, a samim tim i položaja i uloge intelektualaca u „prvom dvadesetom veku". Ono polazi od aktivne uloge kulture i njene relativne autonomnosti naspram tradicionalnih marksističkih čitanja kulture kao odraza ekonomske i društvene stvarnosti. Drugačije kazano, ono prelazi put od socijalne istorije kulture do kulturne istorije društva kako bi se uočila stvaralačka uloga intelektualaca u konstrukciji kako estetskih tako i političkih svetova. Kako svojim obimom ova tema već po sebi nalaže sintetske razmere jedne monografije, ovde ćemo prednost dati onom srpskom, izvornom liberalnom pokolenju, premda u širokoj ravni koja ne isključuje ni neke konzervativne, a ni autore leve provenijencije. Ne samo da je frankofilstvo liberalnog kruga bilo najvidljivije - i po društvenom statusu „Parizlija” (profesora univerziteta, diplomata, pisaca) u srpskoj i potom jugoslovenskoj kraljevini - nego je u godinama pred Drugi svetski rat bilo izloženo nimalo lakoj ideološkoj proveri. Lišen političkih lutanja ekspresionista i nadrealista, ovaj liberalni krug, iako na egzistencijalnom izmaku snage, pokazaće se kao dosledni branilac svojih ranih uverenja. U analizi delovanja intelektualaca u Jugoslaviji poznih tridesetih godina dvadesetog veka čini nam se, dakle, više nego legitimno da se zapitamo o dubinskom značaju kulturnih transfera iz francuske u srpsku i jugoslovensku sredinu i da na njima proverimo neka od temeljnih pitanja svake istorije intelektualaca kao što su ideološka svrstavanja, angažman, odgovornost.

Kao zasebna istoriografska disciplina u evropskoj istoriografiji, istorija intelektualaca je morala da sačeka odumiranje sartrovskog modela krajem sedamdesetih godina prošlog veka, odnosno trenutak koji je umnogome označio kraj figure angažovanog intelektualca uopšte. Neobičnom ironijom, „smrt intelektualca” odgovarala je promeni paradigme u

O ukupnom značaju francuskih političkih i kulturnih ideja za razvoj moderne Srbije tokom 19. i početkom 20. veka vidi: Dušan T. BATAKOVIĆ, Les sources françaises de la démocratie serbe 1804-1914, Paris 2013. 
društvenim naukama: nakon šezdesetih i sedamdesetih godina i interesovanja za strukture, mentalitete, kolektivno, za dugo trajanje i istoriju odozdo, ponovno buđenje interesa za pojedinca i povratak naraciji omogućili su osamdesetih godina, naročito u francuskoj istoriografiji, rađanje jednog novog elana: studija o intelektualcima na razmeđu političke, društvene i kulturne istorije. Polazeći najčešće od političkog angažmana i distancirajući se od socijalnog determinizma i drugih evropskih tradicija u proučavanju uloge „inteligencije", istorija intelektualaca je prvenstvo dala proučavanju intelektualnih generacija (génération), mreža (réseau) i životnih putanja (itinéraire), zatim konceptima društvenosti (sociabilité). ${ }^{3}$ Kao rezultat Radne grupe za istoriju intelektualaca (Groupe de travail sur l'histoire des intellectuels) koju je u okviru Institut d'histoire du temps présent 1985. u Parizu pokrenuo Žan-Fransoa Sirineli (Jean-François Sirinelli), a naročito Grupe za istraživanje istorije intelektualaca (Groupe de recherche sur l'histoire des intellectuels) pod vođstvom Mišela Trebiča (Michel Trebitsch) i Nikol Rasin (Nicole Racine) koja joj je sledila krajem 1980-tih, francuska istoriografija je razvila inovativan i sveobuhvatan pristup u novoj disciplini. Sa naglašenom komparativnošću, ovo usmerenje je dovelo do metodoloških i konceptualnih uobličenja izloženih u mnogobrojim publikacijama, a posebno u zborniku-manifestu $\mathrm{Za}$ komparativnu istoriju intelektualaca (Pour une histoire comparée des intellectuels), pod uredništvom Mišela Trebiča i Mari-Kristin Granžon (Michel Trebitsch, Marie-Christine Granjon). Tako Kristof Šarl (Christophe Charle) ističe da svaka kulturna istorija, naročito u savremenom dobu, može jedino da bude komparativna, jer se kulture određuju jedne prema drugima, i to ne samo „manje” prema većima, „dominantnim i koje imaju univerzalističke pretenzije kao što je francuska kultura". ${ }^{4}$

Poslednjih godina, međutim, u francuskoj istoriografiji primetan je uspon intelektualne istorije koja je usredsređena na opus intelektualaca, odnosno na sadržaj njihovog literarnog, umetničkog ili naučnog dela naspram samog angažmana koji intelektualac zauzima. Težeći srednjem rešenju, a sa bogatim nasleđem u anglosaksonskoj i američkoj istoriji ideja, intelektualna istorija nastoji da poveže dela i autore sa specifičnim kontekstima u kojima su se razvijali. Problematizujući je $s$ aspekta istorijske biografije, ovu tendenciju uspešno predstavlja Fransoa Dos (François Dosse), koji u knjizi Biografija kao izazov (Le Pari biogaphique) analizira smenu biografskih modela: od herojskog, plutarhovskog, preko modalnog (u kome je ličnost odraz jednog društva) do hermeneutičkog, koji uvažava „pluralizam identiteta”, promenljivost i evolutivnost koje ličnost može da iskusi tokom životnog puta. Svi pomenuti elementi, dakle, upućuju na vrlo zapažen status istorije intelektualaca i intelektualne istorije u savremenim istoriografskim kretanjima, a koji se i u našoj temi javlja kao neophodni diskurzivni okvir.

Francusko-jugoslovenski odnosi u međuratnom periodu označeni su ambivalentnošću karakterističnom za odnos velike sile i važnog, ali malog saveznika. U duhu versajskog sistema, Francuska i Jugoslavija su bliske saveznice, posvećene očuvanju evropskog mira.

François DOSSE, „Histoire intellectuelle”, Historiographies, I. Concepts et débats, (ur. Christian Delacroix, François Dosse, Patrick Garcia i Nicolas Offenstadt), Paris 2010., 380.-381.

4 Christophe CHARLE, „L'histoire comparée des intellectuels en Europe”, Pour une histoire comparée des intellectuels, (ur. Michel Trebitsch i Marie-Christine Granjon), Paris 1998., 56. 
U temeljima njihovog odnosa nije od malog značaja vojno savezništvo Francuske i Srbije tokom Prvog svetskog rata. Štaviše, i u Francuskoj i u Jugoslaviji između dva rata, taj narativ je posebno negovan. Međutim, iako Jugoslavija, kao jedan od stubova Male Antante, pronalazi svoje mesto u francuskoj srednjoevropskoj i istočnoj politici, kompleksnost odnosa Francuske i Italije, kao i revizionističke ambicije koje okružuju jugoslovenske granice, dovode do trajnih problema u francusko-jugoslovenskim odnosima. Vidljivi još za vreme kralja Aleksandra Karađorđevića, oni će biti pojačani nakon njegove smrti 1934. Pred nemačkom privrednom ekspanzijom, Francuska će u drugoj polovini 1930-tih izgubiti svoje nekada neprikosnovene političke pozicije. ${ }^{5}$

Kulturni odnosi, međutim, otvaraju jednu zasebnu perspektivu. Njihova dinamika ne prati nužno ritam političkih odnosa, iako je njime takođe uslovljena. Drugim rečima, primeri koje ćemo ovde izneti ukazuju na trajne uporišne tačke koje su liberalni intelektualci u Kraljevini Jugoslaviji pronalazili u francuskoj civilizaciji i dodatno ih afirmisali krajem 1930-tih.

Kao uvodna predstava poslužiće nam nekoliko duhovnih zapitanosti o Francuskoj iz 1937. i 1938. „U duhovnom životu potrebno je dopunjavanje i ne treba ga uvek shvatiti kao prevlast jednog naroda nad drugim", zapisao je Stanislav Vinaver 1937. godine. ${ }^{6}$ Otvarajući svoj esej o Francuskoj ovim motom, on je crtao privlačnost zemlje: „Francuska je imala sve evropske mistike, sve evropske zanose, sve evropske fanatizme." ${ }^{7}$ Suviše dobro upućen u duhovna vrenja Francuske tridesetih godina, Vinaver je, takođe, primećivao da u tome času „Francuska nije ta, koja sprovodi u svetu novu arhitekturu, pojmova vere i mistike”. ${ }^{8}$ Štaviše, političke i intelektualne podele u Francuskoj dovele su do preispitivanja i odbacivanja nekih od njenih najvećih tekovina. Tako istaknuti katolički autori, zapaženi na krajnjoj morasovskoj desnici, poput Anri Masisa (Henri Massis), „odbacuju u ime Francuske i najveći deo onih vrednosti za koje smo mislili da su najvećma francuske. Pre svega, oni odbacuju francusku revoluciju, sa svima njenim posledicama". Vinaver, međutim, uzdiže jednu drugu Francusku, onu Aristida Brijana (Aristide Briand) i Leona Bluma koja

(...) nesumnjivo će ostvarivati, vremenskome pijanstvu uprkos, stalno i budno, vizije svesne i jasne, tajanstvene i mistične, koje će nas stvaralački primicati stanju pravoga i prostoga konačnog iskustva o tome, da je Evropa jedna i onda, kad je najviše zavađena i onda kada to niko u Evropi ne bi znao niti hteo da prizna. ${ }^{10}$

Francusko „venčanje tradicije i slobode” merilo je, prema Vinaveru, najvećeg uspeha Francuske „koji joj osigurava kontinuitet, nepretrgnutost i onde gde su sve ostale kulture pod znakom pitanja, i pred gubljenjem živaca i čula." 11

\footnotetext{
O francusko-jugoslovenskim odnosima vidi: Jugoslovensko-francuski odnosi: povodom 150 godina od otvaranja prvog francuskog konzulata u Srbiji, Beograd 1990.; Jean-Noël GRANDHOMME - Jean-Paul BLED - Vojislav PAVLOVIĆ, „Les relations franco-yougoslaves dans l'entre-deux-guerres (1918-1940)”, Études danubiennes, 23/2007., br. 1-2, 21.-32.; Stanislav SRETENOVIĆ, Francuska i Kraljevina Srba, Hrvata i Slovenaca 1918-1929, Beograd 2008.; Dušan T. BATAKOVIĆ (ur.), La Serbie et la France une alliance atypique: relations politiques, économiques et culturelles 1870-1940, Belgrade 2010.

Станислав ВИНАВЕР, „Непретргнута Француска (I)”, Сриски књижевни гласник, 18/1937., knj. LI, br. 6, 453. Isto, 454.

Isto, 455 .

Isto.

$10 \quad$ Isto, 460.

11 Станислав ВИНАВЕР, „Непретргнута Француска (II)”, Српски книжевни гласник, 18/1937., knj. LI, br. 7, 561.
} 
U još oštrijim, življim potezima pronalazimo jednog Bogdana Radicu, koji brani uspavanu liberalnu Francusku: „Baresovski 'Kult de Moa', njegov kosmopolitizam s kraja stoleća, koji se u jednom trenutku izdigao i postavio 'o servis de la nasion', istaknuvši krajnji nacionalizam, završava danas u krajnostima Monterlanova egotizma i 'anarhijskog morala". ${ }^{12}$ $S$ jedne strane ekskluzivni katolicizam, a s druge ne manje beskompromisni komunizam, mladi koji gledaju u Berlin, Rim, Moskvu, donose sumrak „Republike Profesora”. Ipak, između „ta dva krajnja pola postoji humanizam, stav 'ljudi dobre volje', Romenov unanimizam i jedna neodređena čežnja za povratkom ka čovečanskome". ${ }^{13}$ Radica je svestan da „fenomen Moras” „proizlazi iz jedne pukotine”: ${ }^{14}$

Pariz se igra sa slobodom, sa prevelikom slobodom, sa redom i sa principima, koji leže u njegovim osnovama. Pariz se odriče svake svoje misije u Evropi. Pariz hoće da žrtvuje svoju idejnu poziciju da bi sačuvao svoj fizički egotizam, nesvestan, da se njegova opstojnost sastoji u njegovoj ideji, da se sva njegova superiornost nad ostalim gradovima evropske geografije obeležava u njegovoj duhovnoj zvezdi, u odblesku njegova duha i u upečatku njegova stila. ${ }^{15}$

U drugačijim bojama Antun Bonifačić slika dileme jednog Pola Valerija. U krizi evropske civilizacije, „tome sukobu individualizma i mistike”, piše Bonifačić, „izgledaju nam često pobornici univerzalizma i neafektivnog svijeta kao nehotični i zakrabuljeni branitelji vlastitih mistika. Progres spada također u takve mitose."16 Iako netipičan primer, „Valéry je zapravo ipak samo izdanak liberalizma prošloga vijeka, premda nema apsolutne vjere u progres niti u nauku. Zato nailazimo sve češće na njegov strah pred budućnošću.” Bonifačić, za razliku od Vinavera, ne veruje u trajne odlike Francuske koju oličava Valeri:

Duhovni kapital svijeta možda će opet promijeniti svoje središte po neumoljivim zakonima starenja i kulturnih ciklusa. Valéry se nalazi na kraju jednoga kruga, ali i tu kao i u prirodi možemo doživjeti razne mutacije, pomjeranje terena i obnovu na istome tlu na drugim principima. Mutno i neracionalno je vječni obnavljač i pokretač a „život mjenja pojedince kao košulje". ${ }^{17}$

Ove tri slike sažimaju različitost pogleda na Francusku i njene duhovne vibracije s kraja tridesetih godina prošlog veka. U njima su prisutne i Vinaverova vera u večnu Francusku, Radičina strepnja zbog kraja jednog sveta, kao i Bonifačićeva okrenutost iracionalnom potresu koji smenjuje francusku civilizaciju sklada i poretka. Intelektualni život u Kraljevini Jugoslaviji, dakle, vidno je uronjen u kulturne borbe Evrope, svedoči o pluralizmu domaće idejne scene, kao i profilisanju divergentnih intelektualnih i političkih pozicija. Međutim, ustaljena i već podrazumevajuća slika međuratne Evrope - i Francuske kao jednog od njenih najlepših ogledala - u liku zarobljenice između tradicije i modernosti, uslovila je česte teleološke poglede na njen, pak, neobično bogat kulturni život. Viđena tek kao predah unutar jednog dugog evropskog građanskog rata, ona je gubila ne samo od živosti svojih strujanja, nego je bila označena kao nemoćna i osuđena na propast. Imajući u vidu političke

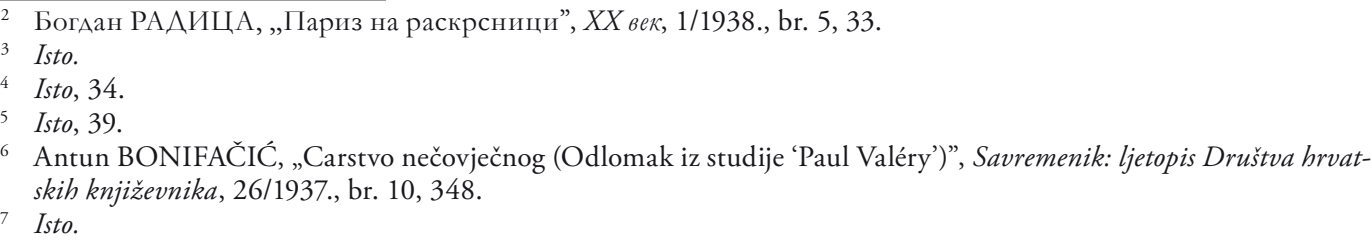


borbe koje su je razarale, a potom i tektonske potrese koji su je kroz Drugi svetski rat izveli ka komunističkoj revoluciji - i dugotrajnom, revolucionarnom čitanju njene prošlosti - Jugoslavija nije bila izuzetak. Usek koji su donele četrdesete godine, izveo je sa scene liberalni kulturni krug, videći u tome neumitni silazak građanske klase iz središta politike i kulture u kome je bila proteklih decenija. Po svom licu i duhovnim afinitetima, ovaj liberalni krug je, međutim, pripadao evropskom trenutku i bio sazdan prema evropskim merilima. Predosećajući buru, Isidora Sekulić je janurara 1941. godine pisala Milanu Grolu:

Godina što ide, neće biti dobra, ali će biti istoriska. Uopšte, živeli smo i dosada vremena u kojima je trebalo misliti, raditi, stradati. En somme, vokacije izuzetne generacije. Ili smo to, ili su izuzetne istoriske epohe došle da nas istrebe zato što nismo to. ${ }^{18}$

Pretežno opoziciono usmereni i van neposrednih političkih tokova, ali gravitirajući prema Demokratskoj, Republikanskoj i Zemljoradničkoj stranci, blagonakloni prema jugoslovenskom okviru i saradnji, kulturnom uzdizanju jugoslovenske celine, liberalni krug srpskih intelektualaca bi se u mnogo čemu mogao dovesti u vezu sa težnjama njihovih francuskih savremenika. Generacijski posmatrano, posredi su intelektualci rođeni do 1885. koji su zrelost dostigli pre Prvog svetskog rata, dakle, u razdoblju parlamentarne monarhije u Srbiji 1903 - 1914. Njima se u međuratnom periodu pridružuje i generacijski krug rođenih između 1885. i 1900, a koji se uglavnom formirao tokom Prvog svetskog rata. Sociološka istraživanja pokazuju da je poreklo ovog liberalnog kruga uglavnom iz predratne Srbije, iz viših i srednjih društvenih slojeva; njih dve trećine školovano je na inostranim, romanskim, prevashodno francuskim univerzitetima. Reč je naročito o pravnicima, književnim istoričarima i kritičarima, književnicima, umetnicima, univerzitetskim profesorima, među kojima su najkrupnija imena Bogdana i Pavla Popovića, Jovana Dučića, Milana Rakića, Branka Lazarevića, Milana Kašanina i dr. Okupljeni na Univerzitetu u Beogradu, posebno Filozofskom i Pravnom fakultetu, Srpskoj kraljevskoj akademiji, zatim oko časopisa Srpski književni glasnik i Misao, ova grupacija zauzima neobično veliki društveni ugled u međuratnom periodu. ${ }^{19}$

Zanimljivo je primetiti da se savremena francuska istoriografija okreće zaboravljenim liberalnim intelektualcima međuratnog perioda. Tako se u njima više ne vide samo poraženi akteri u političkim borbama ili avangardnim promenama u francuskoj kulturi, niti simboli dekadencije Francuske pre Drugog svetskog rata, već uzorni poklonici racionalizma, prosvećenosti, pacifizma i evropske saradnje, i tvorci jednog kulturnog modela koji je težio pomirenju i kulturnoj sintezi. ${ }^{20}$ Jedno od lica tog modela je i sveobuhvatni program kulturne diplomatije koju je Francuska sprovodila u svetu od 1920, a veoma intenzivno i u Kraljevini Jugoslaviji. Ne iznenađuje saznanje da je glavnog saradnika u tom poslu imala upravo u liberalnim intelektualcima mlade jugoslovenske kraljevine. ${ }^{21}$

18 „Писма Исидоре Секулић Миману Гролу”, Аетопис Матище српске, 161/1985., br. 4, 460.

19 Milosav JANIĆIJEVIĆ, Stvaralačka inteligencija mecuratne Jugoslavije, Beograd 1984., 184.-195.

20 François CHAUBET, Histoire intellectuelle de l'entre-deux-guerres. Culture et politique, Paris 2006, 7.-12.

21 O francuskoj kulturnoj diplomatiji u Kraljevini Jugoslaviji videti: Veljko STANIĆ, „Les expositions d'art dans la diplomatie culturelle française des années 1930 - le cas yougoslave”, Etudes danubiennes, 26/2010., br. 1-2, 123.-141.; ISTI, „Les instituts français en Yougoslavie à l'époque de l'entre-deux-guerres”, Etudes danubiennes, 28/2012., br. $1-2,73 .-95$. 
Kako bismo izdvojili karakteristične primere važne za našu temu, a koje ne možemo lako ni iscrpeti, usredsredićemo se na tri posebne publikacije objavljene redom 1938, 1939. i 1940. godine.

Još 1937. godine, u Beogradu je pokrenuta Biblioteka Politika i društvo, u izdanju istoimene „Izdavačke zadruge”. Iza ovog poduhvata nalazila se grupa intelektualaca izrazite demokratske orijentacije, profesora Pravnog fakulteta, koju su u prvom redu predstavljali Mihailo Ilić, Milan Žujović i Božidar S. Marković, i koji su zauzimali prominentno mesto među liberalno orijentisanim intelektualcima u Beogradu. ${ }^{22}$ Jedno od pedesetak izdanja ove biblioteke u potpunosti je posvećeno Francuskoj, što čini izuzetak imajući u vidu odsustvo sličnih svezaka kada su druge evropske države i kulture u pitanju. Još važnije je da ona nosi simboličan naslov Francuska 14. juli 1938 i da izlazi u toku godine koja je u Kraljevini Jugoslaviji zvanično proglašena „francuskom” (zbog obeležavanja dvadesetogodišnjice završetka Prvog svetskog rata) - uprkos očiglednom kursu Stojadinovićeve politike. ${ }^{23}$

$S$ čitanjem ove nevelike knjižice, svojevrsnog kompendijuma posvećenog Francuskoj i njenim raznim licima, od politike do umetnosti, s pravom bismo mogli početi i od kraja. Završni tekst, koji otkriva svu angažovanost poduhvata, iz pera je Mihaila Ilića:

Svaki poredak, međutim, pretpostavlja sklad i ravnotežu, koje Francuska doista pokazuje u svakom pogledu, - dok u svetu, na žalost, besne razorne sile i teže da ga udese po svome običaju. Verovati u njihov uspeh, znači ne verovati da će se ljudi ikad vratiti zdravom razumu. (...) Istina, jedna je Francuska na svetu, - ali na narodima je da ih bude više. (...) Zbog sličnog temperamenta i istovetne odanosti i ličnoj i nacionalnoj slobodi, nazivali su nas nekada Francuzima na Balkanu. Kad bismo opet zaslužili, da nas tako zovu! ${ }^{24}$

Ukupno dvadeset dva priloga razvrstana u tri simbolične celine (Stvarnost, Kultura i Francuska i čovečanstvo) donose preglednu i široku političku, društvenu i kulturnu panoramu savremene Francuske. Slobodan Jovanović piše o prvim danima Treće republike i trajnosti njenog ustava; ${ }^{25}$ Đorđe Tasić se nadovezuje na svetli primer koji pruža ,jedna od kolevki demokratije i jedan od njenih najčvršćih stubova". ${ }^{26}$ Milan Žujović sa simpatijom slika francuskog bourgeois i njegovu težnju ka nezavisnosti, marljivosti i štedljivosti, kao i „njegovoj ljubavi za otadžbinu i za slobodu." ${ }^{27}$ Nedeljko Divac i Mladen Josifović ističu zasluge koje Francuska ima u razvoju radništva i poboljšanju njegovog položaja, ${ }^{28}$ kao i ulozi koju igra njeno selo; ${ }^{29}$ Ljubomir Radovanović temeljnu prednost Francuske u Evropi vidi u njenom upravnom uređenju, ${ }^{30}$ kojima se pridružuju pravni ${ }^{31}$ i školski sistem. ${ }^{32}$

\footnotetext{
M. JANIĆIJEVIĆ, Stvaralačka inteligencija meduratne Jugoslavije, 189.-191.

23 Vlada Milana Stojadinovića (1935-1939) vodila je politiku zbliženja sa Italijom i Nemačkom, radeći pre svega na razvoju privredne, ali i političke saradnje. Iako Francuska i u drugoj polovini 1930-tih zadržava važne pozicije u Jugoslaviji, Stojadinovićeve godine faktički označavaju kraj privilegovanog francusko-jugoslovenskog savezništva koje je trajalo od završetka Prvog svetskog rata do ubistva kralja Aleksandra u Marseju 1934.

24 Ар. Михаило ИАИЋ, „Човек у Француској и Француска у Човечанству”, Франиуска 14. jули 1938, БеограА 1938., 197.-198.

25 Слободан ЈОВАНОВИЋ, „Постанак Треће Републике”, Франиуска 14. јули 1938, 5.-16.

26 Ар. Ђорђе ТАСИЋ, „Уставни пореАак”, Франиуска 14. јули 1938, 17.

27 Ар. Милан Ј. ЖУЈОВИЋ, „Средњи Аруштвени слојеви”, Франиуска 14. јули 1938, 28.-29.

28 Ар. Недеько АИВАЦ, „РаАништво и синдикаАни покрет”, Франиуска 14. јули 1938, 32.-41.

29 Ар. Младен ЈОСИФОВИЋ, „Село и мере за његово подизање”, Франиуска 14. jули 1938, $42 .-51$.

30 Фубомир РААОВАНОВИЋ, „Основна обележја административног уређења”, Франиуска 14. јули 1938, 63.-70.

31 Ар. Михаило КОНСТАНТИНОВИЋ, „Позитивно право и основи приватноправног поретка”, Франиуска 14. јули 1938, 71.-77.

32 Раноје . КНЕЖЕВИЋ, „Школски систем”, Франиуска 14. јули 1938, 78.-86.
} 


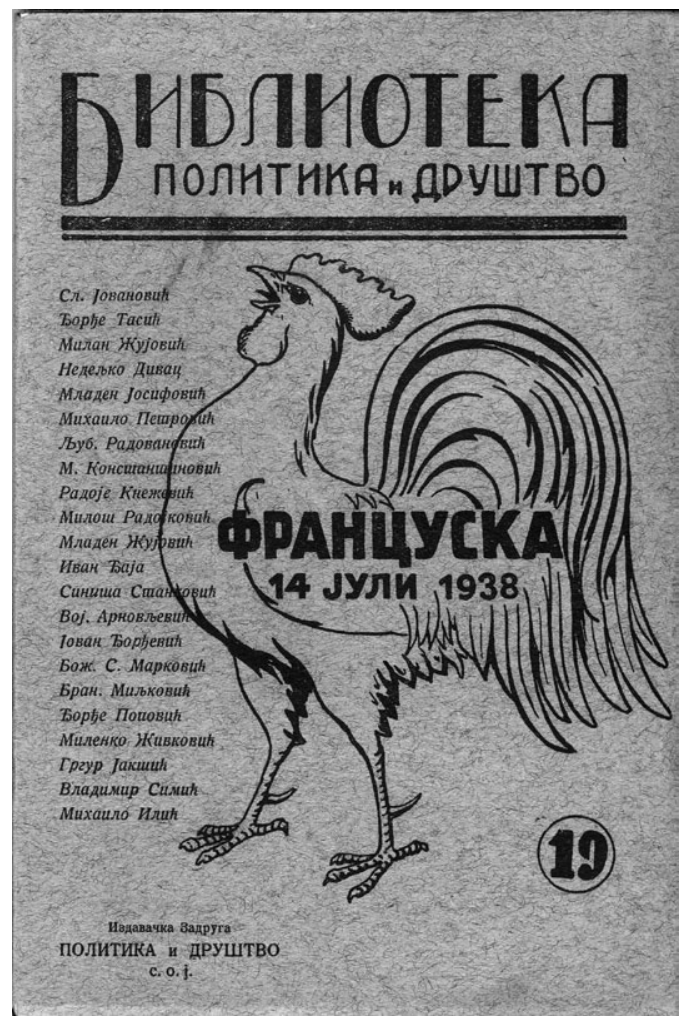

Slika 1. Srpska intelektualna elita Francuskoj Republici povodom njezinog nacionalnog praznika, 14. srpnja 1938.
Iako informativni, prilozi u ovoj knjizi nisu lišeni neposredne političke poruke koju nose. Naprotiv, prisutni idealizam najlepše odslikava i snagu ubeđenja i moć iluzije: „Načela Deklaracije prava čoveka i građanina još i danas ako ne upravljaju životom svih evropskih naroda ono bar predstavljaju ideal kome oni teže”"33 ili: „Francuska [je] danas jedna od onih zemalja u kojoj je narodno jedinstvo najpotpunije, a državna zajednica najčvršća." ${ }^{34} \mathrm{U}$ istom duhu, senka ne pada ni na francusku vojnu moć. U njenom oficirskom kadru vidi se „najnesumnjivija superiornost francuske vojske”, a „francusko-britanski blok raspolaže otsada jednom ogromnom snagom, koja se iz dana u dan sve više usavršava. Ove dve sile predstavljaju garantiju mira i njima će se pridružiti snage miroljubivih naroda. Kada svet bude svestan njihove nepobedivosti biće nam dopuštene sve nade u bolje dane." 35

Francuska snaga je, međutim, prvenstveno u njenoj kulturi. Branislav Miljković se pita „da li je pravo i opravdano ono tvrđenje da je francuska kultura ostarila i omalokrvila, da njene bitne osobine - ukoliko se one uopšte mogu pohvatati i uobličiti - ne odgovaraju današnjim duhovnim potrebama sveta” ${ }^{36}$ Odgovor nije potvrdan. Miljković se suprotstavlja trenutku u kome „mahnitaju nacionalne strasti, kad neki glavni ideolozi i vođi ističu 'moralno biće' svoje nacije kao superiorno i suprotno drugima” i ostaje veran „idealu francuske kulture o slobodi čovekove misli i njegovog delanja." ${ }^{37}$ Ivan Đaja takođe u francuskoj nauci vidi prevashodno njen univerzalni duh. Đaja piše:

Francuska je nauka bila vođena verom da od nje treba očekivati trajno dobro. Danas, na žalost, ni najnaivniji idealista ne može više u to verovati. (...) Idealizam nije više na ceni danas. Mnogi se hvale svojim realizmom a na idealizam gledaju kao na opasnu i jalovu slabost. ${ }^{38}$

On, međutim, nedvosmisleno dodaje:

I danas treba više nego ikada isticati realnost ideala. Jer nijedna velika stvarnost nije potekla iz odsustva idealizma. (...) Sloboda, jednakost, bratstvo, dabogme da su u apsolutnom

\footnotetext{
Ар. Мимош РААОЈКОВИЋ, „Смернице споьне политике”, Франиуска 14. јули 1938, 88.

Мих. С. ПЕТРОВИЋ, „Политичке странке”, Франиуска 14. јули 1938, 53.

Ар. Мцаден Ј. ЖУЈОВИТ, „Војна снага”, Франиуска 14. јули 1938, 103.

Бранислав МИљКОВИЋ, „Животна снага француске културе”, Франиуска 14. jули 1938, 149.

Isto.

38 Ар. Иван ЂАЈА, „Аух науке”, Франууска 14. јули 1938, 112.
} 
smislu utopije. Ali se u njih mora verovati, da bi bilo malo manje ropstva, malo manje nejednakosti i malo manje mržnje. ${ }^{39}$

Siniša Stanković piše o pozitivizmu i humanizmu u francuskim prirodnim naukama, ${ }^{40}$ a Jovan Đorđević pregnantno, ali i obavešteno, o društvenim naukama i njihovim glavnim odlikama: pozitivizmu, objektivnosti, relativizmu, solidarnosti „metoda i nauka”, „internacionalnom duhu” i humanizmu. ${ }^{41}$ Najzad, ovako optimistično izvedena slika Francuske data je neraskidivo od domaćih, jugoslovenskih potreba. Francuska od Revolucije 1789. i nacionalna borba „Jugoslovena” deo su jedne borbe

(...) za politička, građanska i ljudska prava, za ustavni, parlamentarni i demokratski poredak, za narodnu vladavinu i socijalnu pravdu (...) Jer naš narod intuitivno oseća i zna, da napuštanje ovoga i ovakvoga istorijskoga hoda ka budućnosti, ne samo da bi unakazilo njegovu moralnu i etičku ličnost, već bi neminovno i sudbinski porušilo temelje na kojima je on počeo izrađivanje svoje nezavisnosti i slobode i na kojima jedino može da počiva. ${ }^{42}$

Drugi primer koji ovde želimo da prikažemo je specijalni dvobroj Letopisa Matice srpske iz jula-avgusta 1939. posvećen Francuskoj. On je, naime, priređen nakon proslave stopedesete godišnjice Francuske revolucije, organizovane te godine i u Beogradu, Zagrebu i Ljubljani, pod predsedništvom Grgura Jakšića.

Ovaj specijal Letopisa otvara prilog Bogdana Popovića U slavu Francuske (u pitanju je govor iz 1938, sa proslave „Francuske godine”), koji pitanje „kulturnog duga Francuskoj” prevodi sa elitnog na narodni nivo i uvodi pojam „instinktivnih simpatija” između dvaju naroda. Popović želi da prikaže jedan trajni afinitet svojih sunarodnika prema Francuskoj kao prvoj kulturnoj sili čovečanstva i da, u osetljivom političkom trenutku, podvuče nepokolebljivost domaćeg javnog mnjenja kada je Francuska u pitanju:

Francuski narod, zatočnik mira, pravde i slobode, i naš dobrotvor, može biti uveren da u nama ima vernog i zahvalnog prijatelja i poštovaoca; da zahvalnost naša nije upisana samo u moćnom bronzanom spomeniku Meštrovića na Kalemegdanu, no da je, čvršća i trajnija od bronze, urezana i u srce naroda. ${ }^{43}$

Ni najmanje ne čude ni članci Jaše Prodanovića i Marka Cara posvećeni Revoluciji 1789, čije vrednosti Prodanović kontrastira savremenoj Evropi u kojoj „danas većina država živi pod diktatorskim režimima”. "Ta piramida, danas”, veli, pak, Car, „čvrsto stoji i pobornicima slobodarskih tekovina pruža solidnu bazu za odbijanje reakcionarnih navala, pa ma s koje strane one dolazile". ${ }^{45}$ Da je veliki sukob u Evropi neminovan, vidi se i iz teksta Jovana M. Jovanovića: „Francuz može da kupi kapu u Londonu i obrnuto, ali francuska kapa ne ide na glavu nemačku, kao ni obrnuto nemačka na francusku glavu. Ovo nije priča, to je stvarnost.”46 Jovanović zabrinuto zaključuje: „Sve može biti, ali još ne može biti izmirenja između Galije i Germanije." ${ }^{\prime 3}$ 
Pored starijih i konzervativnijih Popovića i Cara i republikanca Prodanovića, u ovom broju su i radovi znatno mlađih integralnih Jugoslovena Vladimira Dvornikovića ${ }^{48}$ i Nika Bartulovića. ${ }^{49}$ Uzimajući u razmatranje „etnogenetičko, 'stratigrafsko' gledanje” u razvoju francuskog naroda, Dvorniković zaviruje u karakterologiju Francuza:

Brzi prelaz iz idejnog, zamišljenog, u motorno, aktivno, čini Francuza impulsivnim, ali i nestalnim. Lepa fraza, oštra misao, živa slika može brzo da ga pokrene, i zato se Francuz može vatreno da oduševi onde gde će drugi, teoretik i flegmatik, konstatovati tek jedno saznanje. Francuzi su klasičan narod ideologa i boraca: od filozofskih sistema do barikada u njih je relativno kratak razmak. Samo ovaj psihološki pogled objašnjava nam zašto je Francuska revolucija postala velikim i tipičnim primerom socijalne, na ideologiji osnovane, revolucije. ${ }^{50}$

Posebnom oštrinom odlikuje se Bartulovićev tekst; njegove reči su reči ideologa koji upozorava, ali i poziva:

Stopedesetgodišnjica Velike revolucije, igrom sudbine, pada sred najreakcionarnije recidive, što ih je svet nakon Revolucije doživeo. (...) Danas se, naprotiv, nasilje uzdiže na pijedestal ideologije i, što je najgore, čitava krda tobožnjih intelektualaca dala su se upregnuti u heliogabalska kola, proklamujući intelekat i duh nesposobnim da određuju sudbinu čovečanstva, i tražeći da se na njihovo mesto, kao vrhovna božanstva, izdignu tenk, plinska bomba i koncentracioni logori. ${ }^{51}$

Sa pozicija svog poznatog jugoslovenskog nacionalizma, Bartulović odriče prestiž nacionaliste prikrivenim ili otvorenim pristalicama fašizma u jugoslovenskoj sredini, uzimajući upravo primer odnosa prema Francuskoj revoluciji:

Dok su se nosioci istinskog i delotvornog nacionalizma, pred rat i za vreme rata - oni oko Revolucionarne omladine, Slovenskog Juga, Pijemonta, Mlade Bosne, koji su davali mučenike, atentatore i dobrovoljce - ponosili da su direktni potomci Velike revolucije, majke svih sloboda i svih težnji ka pravdi i napretku - danas se sa strane ljudi koji tvrde da su jedini uzeli monopol na nacionalizam, jednako kao i sa strane izvesnih služničkih komiteta, sipa paljba na Revoluciju kao početak svih zala u svetu, pa nam se, umesto uzvišenog gesla „Bratstva, jednakosti i slobode”, serviraju parole životnih prostora, nejednakosti ljudi i rasa, i potrebe da mali narodi budu plen za apetite velikih. ${ }^{52}$

Završetak je prirodno optimistički, s dosta patosa i previše vere i u Francusku i u Jugoslaviju:

Jer i naši ratovi za oslobođenje bili su uvek svesne revolucije čitavog narodnog kolektiva protiv ropstva i tiranije (...) biće svaki naš čovek živa Mažinovljeva i Sigfridova linija, koja će do poslednjeg daha mahnito braniti dragu svoju slobodnu i naprednu Jugoslaviju..$^{53}$

\footnotetext{
48 ВАадимир АВОРНИКОВИЋ, „Револуционарни и конзервативни елеменат у француској психи”, Аетопис Матиче сриске, 37.-47.

49 Нико БАРТУАОВИЋ, „Велика револуција и национална мисао”, Аетопис Матиее сриске, 48.-50.

50 ВАадимир АВОРНИКОВИЋ, „Револуционарни и конзервативни елеменат у француској психи”, Аетопис Maтище сриске, 43.

51 Нико БАРТУАОВИЋ, „Велика револуција и национална мисао”, Аетопис Матиче српске, 48.

52 Isto.

53 Isto, 50.
} 
Poslednji primer u ovom kratkom ogledu je iz 1940. godine. Knjiga o Francuskoj, duhovni brevijar jedne generacije srpskih intelektualaca, je i jedna stara priča o slobodi. Prema Cvijićevim rečima,

(k)ad su se u srpskoj inteligenciji počele javljati prve misli o slobodi i pravima čoveka, o poštovanju koje se mora imati prema ispravnim ličnostima i ličnom dostojanstvu, te misli su na prvom mestu bile francuskog porekla ili inspirisane faktima francuske istorije, naročito Velikom revolucijom. A po jednom dubokom instinktu, koji se događajima poslednjih godina pokazao kao nepogrešan, srpski je narod ostvarenje svoga narodnog ideala vezivao uvek za Francusku, zemlju velikih čovečanskih pokreta i internacionalne pravde. ${ }^{54}$

U dubinskim vezama među ovim narodima, nalazila su se, po Cvijiću, slična iskustva:

Renan je s pravom rekao: da je bitni elemenat ideje o narodnosti i o narodu to kad pojedine njegove grupe ili delovi imaju iste istoriske tradicije, kad su vezane istim nasledstvom sjajnih i slavnih događaja, kao i nesrećama i dubokim žalostima koje su ih snalazile. Mi smo takvim sponama i događajima vezani sa velikim francuskim narodom, i naše prijateljstvo prelazi obične i čak tesne veze koje se inače javljaju između naroda. Ono ima mnogo dublju, neizgladljivu podlogu. ${ }^{55}$

Pripremljena i objavljena pred leto 1940. godine, Knjiga o Francuskoj je verovatno poslednji omaž zemlji koja nestaje pred nemačkim oružjem. U njoj su sabrani tekstovi iz različitih perioda, dati kao svedočanstvo vremena i zalog trajnosti. Ali pogled na Francusku dat je ovde u jednoj povlašćenoj perspektivi, onoj francusko-srpskog i francusko-jugoslovenskog zajedništva u novijoj istoriji. S udaljenosti od sedam decenija, u svemu što danas može da zazvuči arhaično i nespretno, uvodne reči ne mogu a da ne odaju izvorni idealizam:

Ova knjiga posvećena je Francuskoj, njenim duhovnim i građanskim vrlinama, njenom skladnom, slobodnom i čovekoljubivom geniju. Ona je izraz nepokolebljivosti francuskojugoslovenskog prijateljstva. Zadatak joj je da pred novim naraštajima osveži bolne i drage uspomene iz nedavnih herojskih dana, kako bi ta svetla zajednička prošlost bolje obasjala puteve naše budućnosti. ${ }^{56}$

\footnotetext{
54 Јован ЦВИЈИЋ, „Француско-српско пријатеьство”, Книга о Франиуској, БеограА 1940., 253.

55 Isto, 254.

56 Kнига о Франиуској, 7.
} 
Vođena Montenjevom mišlju da reč jednom polovinom pripada onome koji govori, a drugom onome koji sluša, Isidora Sekulić u „francuskom geniju” vidi stalnog sabesednika, u slobodi, pravdi i lepoti:

Za vreme rata, ona je mešala krv svoju s našom, grobove svoje s našima, trofeje svoje $s$ našima. (...) Ima nas dosta koji smemo reći slobodno, i možemo dokazati, da nas je na duhovnom životnom putu za jednu ruku vodila Francuska, za drugu Srbija. Pravo je da se to kaže maloj Srbiji prohujalih vremena. ${ }^{57}$

Ostvarenje francuske duhovne moći nigde se ne vidi kao u Parizu; u njemu se razlažu i sintetizuju toliki darovi:

Vera ljudi u Pariz tako je stalna i mistična, kao vera u nadživotno i svemogućno. (...) Kao što je Bog svačiji, tako je i Pariz. Ulazite samo, borci i radnici! ulazite, energije i talenti svih podneblja, nacija, generacija! Kapije se ne zatvaraju, radionice se ne zatvaraju. Pariz budno čeka da se iskrcaju sve one treće klase svih sela i planina, budućnost i kontinuitet, mladost šarena u kostimu, nevešta u ponašanju, nevešta da kaže francuskim jezikom drugo do: Pariz, sloboda, lepota, duh. ${ }^{58}$

Francuska je, zatim, jedna idealna sinteza humanističkih ideala, „zemlja visoke prosvećenosti i lepote, slobode i miroljubivosti” ${ }^{59}$ Kulturni i civilizacijski uzor, Francuska je i čuvar jednog neobičnog prijateljstva:

Malo je stranaca koji su nam prišli sa toliko ljubavi, malo je stranaca a malo je i naših ljudi koji su se bavili nama sa toliko pronicljivosti i koji su - može se reći - proročki predvideli našu jugoslovensku budućnost. ${ }^{60}$

Ako bismo se zadržali na ponuđenim teorijskim konceptima s početka ovog rada, primetili bismo da se pomenuti obrasci réseau, itinéraire i sociabilité itekako mogu primeniti na liberalni intelektualni krug koji smo ovde dotakli. Dovoljno je pomenuti Srpski književni glasnik ili termin „Parizlija” kako bismo naglasili samo neke od atributa koji omogućavaju pozicioniranje unutar ovog miljea. Mentalna mapa koju tako dobijamo proteže se na nekoliko decenija (okvirno od kraja 19. veka do Drugog svetskog rata) preuzimanja i preoblikovanja političkih i kulturnih vrednosti iz Francuske koje se povratno manifestuju u primerima koje smo analizirali. Kraj tridesetih godina prošlog veka je tako vreme pojačane pažnje koja se od strane ovog kruga poklanja Francuskoj i to suprotno kursu koji u istom periodu zauzima zvanična jugoslovenska politika. Reč je o par excellence pitanju odgovornosti i naglašavanju dubinskih veza sa francuskom politikom i kulturom koje se projektuju više od jednog stoleća unazad, do Francuske revolucije kao izvora racionalizma, ideala slobode i jednakosti, ali i sinonima evropske civilizacije, njene ravnoteže i harmonije. Veziva-

\footnotetext{
7 Исидора СЕКУАИЋ,, „Француски геније”, Книга о Франиуској, 52.

58 ISTA, „Париз”, Книга о Франиуској, 122.-125.

59 Светислав ПЕТРОВИЋ, „Земьа просвећености и мепоте, слободе и мироьубивости”, Книга о Франиуској, 85.

60 Јемисавета ИБРОВАЦ-ПОПОВИЋ, „Француско пријатељство”, Книга о Франиуско, 188.
} 
nje za Francusku ima dodatni značaj kada se uzme u obzir totalitarni kontekst tridesetih godina, kao i zajednička, ali i pojedinačne sudbine pripadnika liberalnog kruga koje smo ovde sreli, u godinama Drugog svetskog rata - od fizičkog nestanka do marginalizacije, ili, eventualno, (delimičnog) uklapanja u poratni komunistički svet u Jugoslaviji.

\section{$\cos$}

\section{France and the intellectuals from the Kingdom of YugOSLAVIA IN THE LATE I93OS}

This paper focuses on a Serbian intellectual cultural circle in the Kingdom of Yugoslavia which held French culture and its political, ideological and other achievements in particularly high regard. It emerged in early 20th century, in the period of Modernism, when a particular liberal cultural model was formed in the circle around the Srpski književni glasnik. The model, mostly established through the appropriation of French models, corresponded to positivism in science and the Parnassus in art, while politically it gravitated towards the Yugoslav solution to the national question In the interwar period, this circle maintained a central position in Serbian cultural life. Starting with theoretical concepts of comparative history of intellectuals offered by the contemporary French historiography, the paper analyzes periodicals and special editions (Francuska 14. juli 1938, Letopis Matice srpske and Knjiga o Francuskoj) from 1938, 1939 and 1940 to determine the basic imagological features of France as created and perpetuated by this intellectual circle. In the late 1930s, this circle takes a stance towards France which is contrary to the attitude of the Yugoslav government. They emphasize the connection with French politics and culture, which dates back more than a century, all the way to the French revolution as the source of rationalism and the ideals of freedom and equality, which are synonymous with European civilization as such, its balance and harmony. Taking after France in this context has an additional meaning in the totalitarian political circumstances of the 1930s, as do the collective and individual post-war fates of the members of this liberal circle, whose works this paper attempts to analyze. They range from disappearance, to marginalization and at best a (partial) integration into the post-war communist context of Yugoslavia. The paper is a testament to the permanence of cultural transfers from France among liberal Serbian intellectuals. It attempts to contribute to the illumination of the role of the liberal intellectual in the Kingdom of Yugoslavia, his habitus and his intellectual and political engagement.

Keywords: France, Yugoslavia, intellectuals, culture, ideologies, liberalism

\section{$\cos$}

\section{Literatura}

Dušan T. BATAKOVIĆ (ur.), La Serbie et la France une alliance atypique: relations politiques, économiques et culturelles 1870-1940, Belgrade 2010.

Dušan T. BATAKOVIĆ, Les sources françaises de la démocratie serbe 1804-1914, Paris 2013.

Antun BONIFAČIĆ, „Carstvo nečovječnog (Odlomak iz studije 'Paul Valéry')”, Savremenik: ljetopis Društva hrvatskih književnika, 26/1937., br. 10, 345.-348.

Christophe CHARLE, „L'histoire comparée des intellectuels en Europe”, Pour une histoire comparée des intellectuels, (ur. Michel Trebitsch i Marie-Christine Granjon), Paris 1998., 39.-60.

François CHAUBET, Histoire intellectuelle de l'entre-deux-guerres. Culture et politique, Paris 2006. 
François DOSSE, „Histoire intellectuelle”, Historiographies, I. Concepts et débats, (ur. Christian Delacroix, François Dosse, Patrick Garcia i Nicolas Offenstadt), Paris 2010., 378.-390.

Франиуска 14. јули 1938, БеограА 1938.

Jean-Noël GRANDHOMME - Jean-Paul BLED - Vojislav PAVLOVIĆ, „Les relations francoyougoslaves dans l'entre-deux-guerres (1918-1940)", Études danubiennes, 23/2007., br. 1-2, 21.32.

Milosav JANIĆIJEVIĆ, Stvaralačka inteligencija mecturatne Jugoslavije, Beograd 1984.

Jugoslovensko-francuski odnosi: povodom 150 godina od otvaranja prvog francuskog konzulata u Srbiji, Beograd 1990.

Книга о Франиуској, БеограА 1940.

Бранко ААЗАРЕВИЋ, Аневник једнога никога, Аруги део (1947), БеограА 2007.

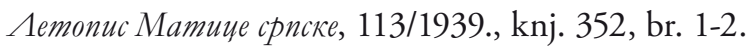

Богдан РААИЦА, „Париз на раскрсници”, ХХ век, 1/1938., br. 5, 31.-39.

Писма Исидоре Секулић Милану Гролу, Аетопис Матиче српске, 161/1985., br. 4, 428.-460.

Stanislav SRETENOVIĆ, Francuska i Kraljevina Srba, Hrvata i Slovenaca 1918-1929, Beograd 2008.

Veljko STANIĆ, „Les expositions d'art dans la diplomatie culturelle française des années 1930 - le cas yougoslave", Etudes danubiennes, 26/2010., br. 1-2, 123.-141.

Veljko STANIĆ, „Les instituts français en Yougoslavie à l'époque de l'entre-deux-guerres”, Etudes danubiennes, 28/2012., br. 1-2, 73.-95.

Станислав ВИНАВЕР, „Непретргнута Француска (I)”, Српски книжевни гласник, 18/1937., knj. LI, br. 6, 451.-464.

Станислав ВИНАВЕР, „Непретргнута Француска (II)”, Српски книжевни гласник, 18/1937., knj. LI, br. 7, 554.-561. 